\title{
Transcriptome profiling of Zymomonas mobilis under ethanol stress
}

\author{
Ming-xiong He ${ }^{1,2^{*}}$, Bo Wu', Zong-xia Shui ${ }^{1}$, Qi-chun Hu' ${ }^{1}, 2$, Wen-guo Wang ${ }^{1}$, Fu-rong Tan ${ }^{1}$, Xiao-yu Tang ${ }^{1}$,
} Qi-li Zhu' ${ }^{1}$ Ke Pan', Qing Li ${ }^{1}$ and Xiao-hong Su'

\begin{abstract}
Background: High tolerance to ethanol is a desirable characteristics for ethanologenic strains used in industrial ethanol fermentation. A deeper understanding of the molecular mechanisms underlying ethanologenic strains tolerance of ethanol stress may guide the design of rational strategies to increase process performance in industrial alcoholic production. Many extensive studies have been performed in Saccharomyces cerevisiae and Escherichia coli. However, the physiological basis and genetic mechanisms involved in ethanol tolerance for Zymomonas mobilis are poorly understood on genomic level. To identify the genes required for tolerance to ethanol, microarray technology was used to investigate the transcriptome profiling of the ethanologenic Z. mobilis in response to ethanol stress.
\end{abstract}

Results: We successfully identified 127 genes which were differentially expressed in response to ethanol. Ethanol up- or down-regulated genes related to cell wall/membrane biogenesis, metabolism, and transcription. These genes were classified as being involved in a wide range of cellular processes including carbohydrate metabolism, cell wall/ membrane biogenesis, respiratory chain, terpenoid biosynthesis, DNA replication, DNA recombination, DNA repair, transport, transcriptional regulation, some universal stress response, etc.

Conclusion: In this study, genome-wide transcriptional responses to ethanol were investigated for the first time in Z. mobilis using microarray analysis.Our results revealed that ethanol had effects on multiple aspects of cellular metabolism at the transcriptional level and that membrane might play important roles in response to ethanol. Although the molecular mechanism involved in tolerance and adaptation of ethanologenic strains to ethanol is still unclear, this research has provided insights into molecular response to ethanol in Z. mobilis. These data will also be helpful to construct more ethanol resistant strains for cellulosic ethanol production in the future.

\section{Introduction}

High tolerance to ethanol is a desirable characteristics for ethanologenic strains used in industrial ethanol fermentation. However, ethanol is generally toxic to microorganisms (such as Saccharomyces cerevisiae, Escherichia coli, and Zymomonas mobilis, etc.), and intracellular and extracellular accumulation of ethanol also inhibits cell growth and metabolism [1-3]. So, ethanol can become a significant stress factor during bio-ethanol fermentation. A deeper understanding of the molecular mechanisms underlying ethanologenic strains tolerance of ethanol stress may guide the design of rational strategies to increase process performance in industrial alcoholic fermentation.

\footnotetext{
* Correspondence: hemxion@hotmail.com

'Biogas Institute of Ministry of Agriculture, Biomass Energy Technology Research Centre, Section 4-13, Renming Nanlu, Chengdu 610041, China ${ }^{2}$ Key Laboratory of Development and Application of Rural Renewable Energy, Ministry of Agriculture, Chengdu 610041, P. R. China
}

Currently, the mechanism of ethanol stress in S. cerevisiae have been studied intensively on cell viability and growth [4], metabolism, cell structure and membrane function [3]. Other studies on transcriptional level also revealed that many genes were more highly expressed in S. cerevisiae during ethanol stress, such as heat shock proteins [5]. Alper et al. found that a global transcription factor SPT15 play a crucial role in yeast ethanol tolerance [6]. Watanabe et al. also reported that general stress-induced genes are under the control of a cisacting factor called the stress response element (STRE) [7]. Further studies directly compared the transcriptomes of stressed and non-stressed S. cerevisiae during short-term sub-lethal ethanol exposure [8-12] also showed that many genes were differentially expressed in the response to ethanol, which related to cell energetics, transport mechanisms, cell surface interactions, lipid 
metabolism, general stress response, trehalose metabolism, protein destination, ionic homoeostasis and an increase in the expression of many glycolysis and TCA cycle-associated genes, etc. [3]. Ogawa et al. identified 271 genes with increased expression during ethanol stress of the ethanol tolerant mutant SR4-3 using microarray technology [13]. Yoshikawa et al. also found 359 ethanol-specific genes by a comprehensive phenotypic analysis under ethanol stress in a collection of yeast strains with a single gene deletion [14].

Compared with $S$. cerevisiae, there are relatively fewer studies regarding ethanol tolerance in bacteria. Gramnegative bacteria usually display an ethanol sensitive phenotype. In $E$. coli, ethanol act as a inhibitor of growth and metabolism, which changes its physical characteristics of cell membrane [15-17]. However, adaptive changes including membrane fatty acid composition, biosynthesis of fatty acid, lipids, peptidoglycan, and outer membrane proteins have reported in response to ethanol stress [17]. For example, the ethanol tolerant mutants (LY01, LY02, and LY03) derivated from engineered E. coli KO11 by laboratory adaptive evolution method showed 50\% survival rate when exposure to $10 \%$ ethanol [18].

Ethanol is also act as a inhibitor of cell growth and metabolism in Z. mobilis, thus resulting in decrease in the rate of sugar conversion to ethanol [2]. Previous studies indicated that the lipid composition of Z. mobilis may represent an evolutionary adaptation for survival in the presence of ethanol [19]. Further research on protein pattern found that differential expression of related proteins are involved in ethanol-shocked responses [20,21]. However, no other studies have examined the response of $Z$. mobilis to ethanol stresses on genomic level. The first genome sequence for $Z$. mobilis ZM4 suggested that a sigma factor $(\sigma \mathrm{E}, \mathrm{ZMO} 4104)$ may play an important role in resisting ethanol stress [22,23]. As a candidate ethanologenic microorganism for converting cellulosic biomass into ethanol or other valuable chemicals, $Z$. mobilis showed many desirable industrial characteristics for its special Entner-Doudoroff pathway [23]. Different engineered $Z$. mobilis strains have also been successfully constructed [24-27] to convert cellulosic biomass into ethanol. Importantly, the complete genome sequence of different Z. mobilis strains (such as ZM4, NCIMB11163, 29192 and 10988, etc.) have been reported since 2005 [22,28-30]. However, the physiological basis and genetic mechanisms involved in ethanol tolerance for $Z$. mobilis are poorly understood. In order to develop new tolerant strains, the mechanisms of $Z$. mobilis in response to ethanol need to be examined and understood, which will provide new insight into tolerance mechanisms and aid future metabolic engineering and synthetic biology in ethanologenic strain improvement. With the completed genome from different $Z$. mobilis strains in hand, comparative genomics or global expression analysis should reveal ways to improve the performance of $Z$. mobilis, and more approaches to strain improvement will certainly be indentified in the future [23].

In this study, microarray technology was used to investigate the expression profiling of the ethanologenic $Z$. mobilis in response to ethanol stress. The results showed 127 genes were expressed up- or down-regulated. These data will help us to understand the molecular mechanisms and provide a global insight into strain improvement by metabolic engineering or synthetic biology.

\section{Results and discussion}

\section{Profiling of cell growth and glucose utilization under} ethanol stress

The presence of $5.0 \%$ ethanol in the medium led to negative impacts on cell growth, glucose consumption of Z. mobilis ZM4 (Figure 1). In the ethanol untreated culture, maximal cell density $\left(\mathrm{OD}_{600}\right)$ reached to 4.5 after approximately $24 \mathrm{~h}$ post-inoculation, while the time of $Z$. mobilis needed to reach its highest cell density of 2.62 $\left(\mathrm{OD}_{600}\right)$ delayed until $36 \mathrm{~h}$ after initial inoculation under ethanol stress conditions. Z. mobilis also consumed glucose more slowly under ethanol stress conditions, nearly $90 \%$ of the initial glucose remaining after $24 \mathrm{~h}$ incubation. In opposite, almost of the glucose has been utilized at this time point under normal conditions. When $Z$. mobilis growth reached its peak after $36 \mathrm{~h}$ under stress conditions, $22 \%$ of the glucose also remained in the culture (Figure 1).

Transcriptome comparision of Z. mobilis under normal and ethanol stress conditions

Seo et al. describe the Z. mobilis ZM4 (ATCC31821) genome as consisting of a single chromosome and

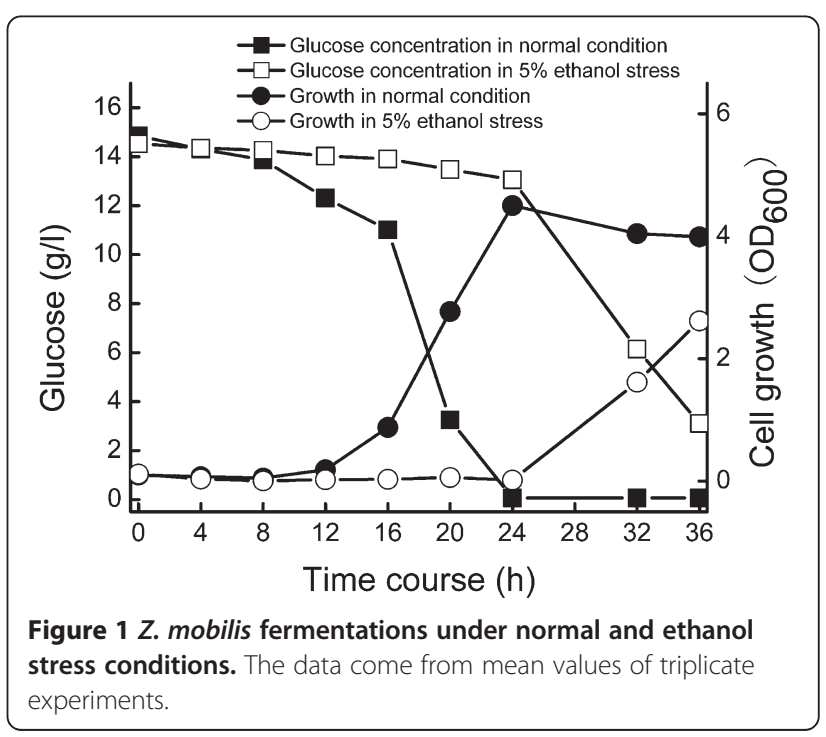


plasmids [22], which we utilized for probe design and microarray fabrication. Therefore, the array data in the present study may fully represent the differences between furfural stress and normal conditions since these plasmid DNA sequences were available. We used a multiplex array format with an average probe length of 36 nucleotides and were able to detect significantly differentially expressed genes.

Based on the genome data of Z. mobilis [22], 1800 gene fragments were amplified by PCR and spotted onto the glass slide. With the sophisticated microarray, the global transcriptional response of $Z$. mobilis ZM4 to ethanol stress was examined at $24 \mathrm{~h}$ post-inoculation under normal (media with no ethanol) and stress conditions (media with $5 \%$ ethanol). Of the 1,800 genes examined by microarray analysis, 127 genes ( $7 \%$ of the total number of open reading frames represented on the array) were identified as being significantly up- or downregulated (fold change $\geq 2.0, P \leq 0.05$ ) during ethanol stress condition. Eighty nine genes were up-regulated after $24 \mathrm{~h}$ post-inoculation under ethanol stress condition and 38 genes were down-regulated (Figure 2 and Additional file

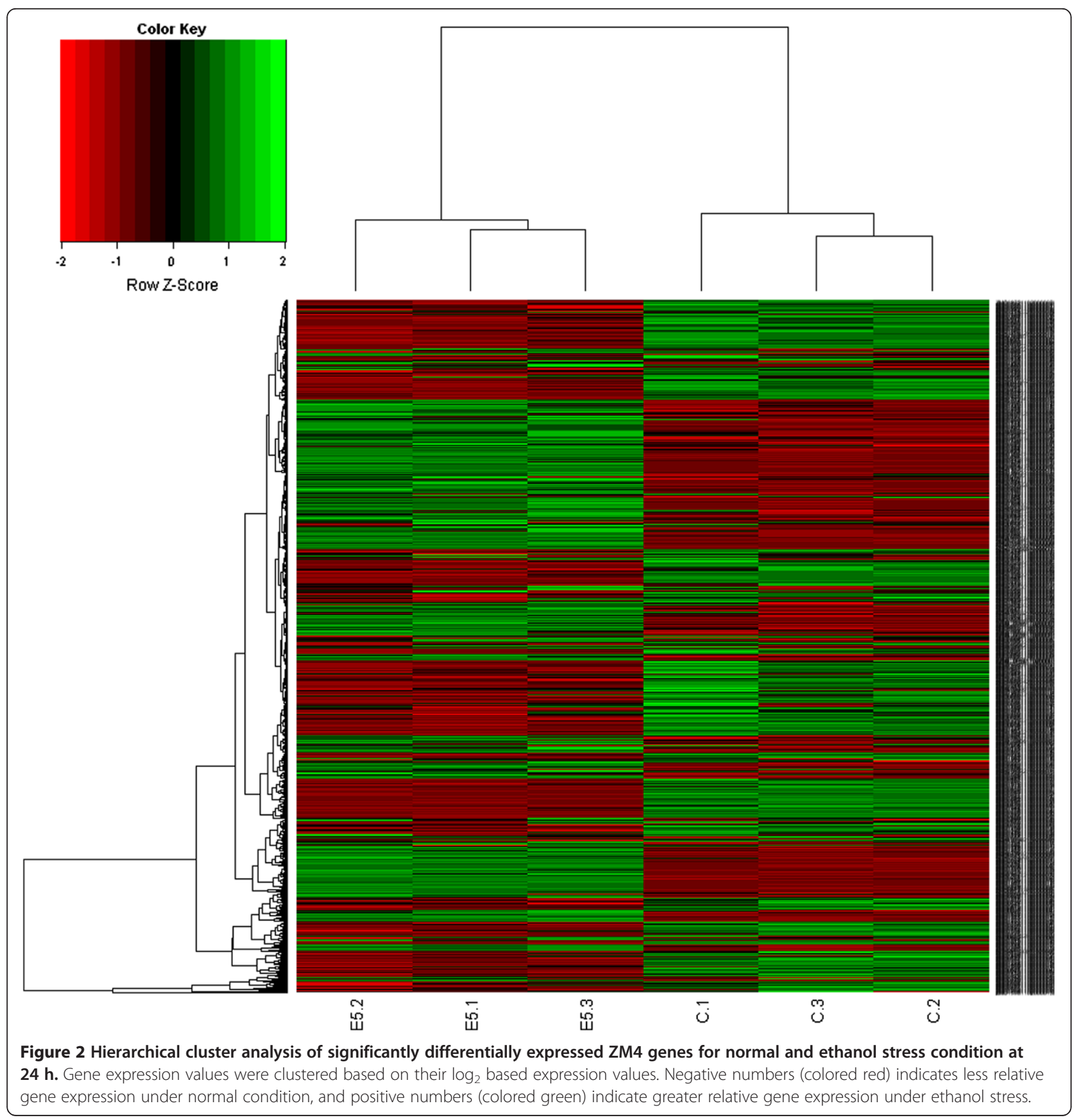


1: S1, Table S1 and S2). Table 1 provides a summary of the percentage of differentially expressed genes grouped by functional categories according to TIGR's annotation of the Z. mobilis genome [22]. We have also deposited the entire microarray data at Gene Expression Omnibus (GEO, http://www.ncbi.nlm.nih.gov/geo/) database with the accession number of GSE39558 so interested parties can conduct their analyses (Please see Additional file 2). Approximately $34 \%$ of the genes down-regulated in the presence of ethanol were related to metabolism. In the presence of ethanol, about $62 \%$ of the genes related to regulation, cell processes, transport, and unknown function showed greater expression as compared to normal conditions. Nearly $24 \%$ of the genes including plasmid encoding genes showing greater expression under stress condition.

To confirm the microarray results, nighteen genes involving in metabolism, information transfer, plasmid encoding genes and hypothetical proteins were chosen for the qPCR analysis (Table 2). The data showed that qPCR was more sensitive with greater differences in comparison to the microarray results (Additional file 1: Figure S2),

\begin{tabular}{|c|c|c|}
\hline COG category & $\begin{array}{l}\text { Up- } \\
\text { regulated } \\
\text { genes }\end{array}$ & $\begin{array}{l}\text { Down- } \\
\text { regulated } \\
\text { genes }\end{array}$ \\
\hline Energy production and conversion & 1 & 5 \\
\hline Cell cycle control & 0 & 1 \\
\hline Amino acid transport and metabolism & 2 & 3 \\
\hline Nucleotide transport and metabolism; & 2 & 0 \\
\hline Carbohydrate transport and metabolism & 2 & 2 \\
\hline Coenzyme transport and metabolism & 4 & 1 \\
\hline Translation & 2 & 1 \\
\hline Transcription & 1 & 2 \\
\hline Replication, recombination and repair & 4 & 0 \\
\hline Cell wall/membrane biogenesis & 4 & 0 \\
\hline Cell motility & 0 & 2 \\
\hline $\begin{array}{l}\text { Posttranslational modification, } \\
\text { protein turnover, chaperones }\end{array}$ & 1 & 1 \\
\hline Inorganic ion transport and metabolism & 2 & 3 \\
\hline General function prediction only & 7 & 4 \\
\hline Function unknown & 4 & 3 \\
\hline Signal transduction mechanisms & 4 & 0 \\
\hline Intracellular trafficking and secretion & 2 & 0 \\
\hline Defense mechanisms & 1 & 0 \\
\hline not in COGs & 16 & 5 \\
\hline plasmid encoding genes. & 30 & 5 \\
\hline Total & 89 & 38 \\
\hline
\end{tabular}

which was in keeping with previous reports [31,32]. On the other hand, genes involving in Entner-Doudoroff (ED) and pyruvate pathways were also chosen for the qPCR analysis, which showed the same results as microarray (data not shown).

\section{Transcripts of Entner-Doudoroff (ED) pathway}

As expected, 23 Entner-Doudoroff (ED) pathway mRNAs such as $g l k, z w f, p g l, p g k$ and eno, as well as ethanol fermentation-related genes like $p d c$ and $a d h \mathrm{~B}$ were shown to be less abundant under stress conditions, but at levels not considered significant. Only two genes of ED and pyruvate biosunethetic pathway were showed significantly down-regulated during ethanol stress (1.5fold change for $g n l$, and 1.1-fold change for $g n t K$, Table 3), which may help us to elucidate its negative effects on cell growth or glucose consumption during ethanol stress. Actually, previous studies have hypothesized that this inhibition is due to direct action of ethanol on key enzymes of glycolysis and ethanol production involving feedback inhibition or enzyme inactivation. However, in vitro studies of these enzymes in $Z$. mobilis and $S$. cerevisiae do not fully support this hypothesis. Further research indicated that inhibition of fermentation by ethanol appears to result from increased leakage through the plasma membrane, allowing loss of cofactors and coenzymes, and also coupled with possible additional leakage of intermediary metabolites en route to ethanol formation [2]. On the other hand, ldhA also showed nearly significantly down-regulated during ethanol stress condition, which may be lead to decrease lactic acid formation (about 50\%) and improve the efficiency of glucose utilization under ethanol stress.

\section{Induction and repression of cell envelope components under ethanol stress}

There are 32 ORFs (ZMO0602-ZMO0652: flgABCDEFGHIJKL, flhAB, fliDEFGHIKLMNPQRS, motAB) encoding flagellar structure proteins, motor proteins and biosynthesis proteins in $Z$. mobilis. As expected, two genes involving in cell motility showed down-regulated under ethanol stress, such as ZMO0613 (flgC, 1.0-fold) and ZMO0614 (flgB, 1.3-fold). Most flagellar-related genes, such as ZMO0604 (flgL), ZMO0605, ZMO0607, ZMO0608 (flgH), ZMO0609, ZMO0610, ZMO0611, ZMO0612, ZMO0619, ZMO0624 (flhA), ZMO0632 (fliE), ZMO0634, ZMO0635 (fliG), ZMO0642, ZMO0643, ZMO0648, ZMO0649, ZMO0651 and ZMO0652 showed also down-regulated under ethanol stress condition.

However, the transcripts encoding MltA domaincontaining protein (ZMO2023), cell wall hydrolase SleB (ZMO0448), peptidase M23 (ZMO0216) and organic solvent tolerance protein ostA (ZMO1311) were shown to be more abundant under stress condition by microarray 
Table 2 Primers pairs used for q-PCR analysis with target gene information

\begin{tabular}{|c|c|c|c|c|c|c|c|}
\hline Primary Locus & Gene & Function & $\begin{array}{l}\text { Forward primer } \\
\left(5^{\prime} \text { to } 3^{\prime}\right)\end{array}$ & $\begin{array}{l}\text { Reverse primer } \\
\left(5^{\prime} \text { to } 3^{\prime}\right)\end{array}$ & $\begin{array}{l}\text { Product } \\
\text { size (bp) }\end{array}$ & ${ }^{\mathrm{a}}$ Array & ${ }^{\mathrm{b}} \mathrm{qPCR}$ \\
\hline ZMO0216 & & peptidase M23 & GACATCACTGGCTTCTAA & GCTGGTTCAAGACGATAT & 104 & 1.1 & 2.6 \\
\hline ZMO0265 & & hypothetical protein & TAAACAGCAGATGACCTT & ATATTGGACCGATTGGAA & 100 & 2.3 & 2.3 \\
\hline ZMO0375 & & levansucrase & TTATGCGGATAGTGAAGG & ACGGAAATTCCAGAGATTA & 115 & 3.0 & 7.2 \\
\hline ZMO0546 & & sulphate transporter & TGTCCTGACTCATAATCT & CGCTTATTCTCTTCATCA & 120 & 3 & 4.8 \\
\hline ZMO0557 & & hypothetical protein & AGATTATCAGGACTGGAA & TAACATTATCAGCATCGT & 113 & 1.5 & 3.1 \\
\hline ZMO1417 & & $\begin{array}{l}\text { DEAD/DEAH box helicase } \\
\text { domain-containing protein }\end{array}$ & TTATTGCCAATGACGAAC & TाTCCATGACAAAGTTTC & 100 & 1.5 & 3.1 \\
\hline ZMO1425 & & thiamine monophosphate synthase & TCATTATCGCTTGCCCTTCA & GAGCCGAATCAGCCAGAA & 101 & 1.1 & 4.9 \\
\hline ZMO1802 & & hypothetical protein & TGCTTATGCAGTGTTTGG & TCAGGAAGGTGTAGAGAC & 94 & 1.1 & 3.5 \\
\hline ZMO1804 & & $\begin{array}{l}\text { amino acid permease-associated } \\
\text { domain-containing protein }\end{array}$ & TTATGGATTTGATACTGTC & CGCTACACCAATATAGAT & 119 & 1.4 & 3.71 \\
\hline ZZM4_0013 & & P2 GpU family protein & GTCACATCCATAGTAGAA & TTATTGTATTGTCGTCATC & 106 & 1.7 & 4.3 \\
\hline ZZM4_0036 & & $\begin{array}{l}\text { protein of unknown } \\
\text { function DUF264 }\end{array}$ & CCAGAATAGTGAAGAAGG & ATCAAGACCTCTAAGTTG & 109 & 1.4 & 1.13 \\
\hline pzmob1_p05 & & hypothetical protein & TTCCAATCGGTTCAATTAGT & CAGCCATAGTATCGGTAAG & 100 & 2.11 & 4.86 \\
\hline pzmob1_p07 & & hypothetical protein & ATGCTGCTTGGTTTGTTA & GTCATCACAATAGGTAGTCT & 107 & 2.66 & 4.09 \\
\hline ZMO1063 & pspA & phage shock protein A & GCCTTATCAGCGATTTATC & GCTTCATTCAACTTATTCTG & 100 & 1.1 & 2.5 \\
\hline ZMO1064 & $p s p B$ & phage shock protein B & TTAGTCTGCCTTATTCTG & CTCATAAAGCTCTTCAATC & 120 & 1.3 & 2.0 \\
\hline ZMO1065 & $p s p C$ & phage shock protein $C$ & AAACCGTTTTCGTGATAT & CGCAAATTATCTATTTCCTT & 96 & 1.2 & 3.0 \\
\hline ZMO0057 & & phage protein & GATAAAGCGACATTAAAGG & TTCATCACCCAGTATTTC & 111 & -1.2 & -3.21 \\
\hline ZMO0062 & & aldo/keto reductase & CAACCCGAATATAATCTTTA & AAGCCAGACTGTAATAAG & 103 & -1.52 & -4.7 \\
\hline \multirow[t]{2}{*}{ ZMO1851 } & & flavodoxin FldA & AAATTGACTGGGAGGATA & GACGAAAGAATCTGGATAA & 110 & -1.93 & -4.7 \\
\hline & End & ogenous control & & & & & \\
\hline ZMOr009 & $\operatorname{rrs} A$ & 16s RNA & TCAACTATAGACCAGTAAGT & AGAACATAGAAGAGGTAAGT & 101 & & \\
\hline
\end{tabular}

${ }^{a}$ Array: the $\log _{2}$ based microarray ratio of the gene expression (ethanol stress/normal).

${ }^{b} \mathrm{qPCR}$ : the $\log _{2}$ based qPCR ratio of the gene expression (ethanol stress/normal).

analysis (see Additional file 1: Table S1). However, other cell wall/membrane biogenesis-related genes, such as ZMO0624, ZMO0641, ZMO0643, ZMO0644, ZMO0647 and ZMO0650 showed less abundant under stress condition by microarray analysis (Data not shown). This suggests that $Z$. mobilis have a adaptive mechanism in response to ethanol stress, which in accordance with previous studies (Z. mobilis could tolerant 13\% ethanol) [17].

Especially, gene enconding putative organic solvent tolerance protein ostA (ZMO1311) showed more abundant under ethanol stress condition, which was in keeping with our previous reports about furfural stress. Further work may be performed by overexpression of this gene to get more tolerant $Z$. mobilis strains for producing valuable chemicals.

\section{Transcripts of respiratory chain genes}

It was reported that $\mathrm{Z}$. mobilis has a respiratory electron transport chain and there are 25 respiratory chain genes. Twelve respiratory chain genes were shown to be more abundant under stress condition, including putative Fe-S oxidoreductase (ZMO0022, 1.09-fold), cytochrome bdtype quinol oxidase subunits 1 (ZMO1571, 1.52-fold), cytochrome bd-type quinol oxidase subunits 2 (ZMO1572, 1.09-fold), Fe-S-cluster redox enzyme (ZMO1032, 1.04fold), cytochrome $c$-type biogenesis protein (ZMO1255, ZMO1256, 1.07-fold), ubiquinone biosynthesis protein (ZMO1189, 1.17-fold; ZMO1669, 1.89-fold), nitroreductase (ZMO0678, 2.53-fold), NADH:ubiquinone oxidoreductase complex (ZMO1812, 1.10-fold; ZMO1813, rnfB, 1.66-fold; ZMO1814, rnfA, 1.47-fold). Interestingly, transcripts of the putative respiratory gene $r n f A$ and $r n f B$, were also illustrated to express more greatly (1.9-fold) under furfural stress condition in our previous sutdies [32].

Other 13 respiratory chain genes were shown to be down- regulated (0.6-0.9 fold) in the presence of $5 \%$ ethanol after $24 \mathrm{~h}$ incubation, including oxidoreductase gene (ZMO1844, 0.51-fold), cytochrome $b$ (ZMO0957), cytochrome $c 1$ (ZMO0958), cytochrome $c$-type biogenesis proteins (ZMO1252-1254), electron transfer flavoprotein (ZMO1479 and ZMO1480), NADH dehydrogenase ( $n d h$, ZMO1113), NADH:flavin oxidoreductase (ZMO1885), 


\begin{tabular}{lll}
\multicolumn{2}{l}{$\begin{array}{l}\text { Table } 3 \text { Transcripts of Entner-Doudoroff (ED) pathway } \\
\text { under ethanol stress }\end{array}$} \\
\hline Primary Locus & Gene & $\begin{array}{l}\text { Fold change in array } \\
\text { experiment }\end{array}$ \\
\hline ZMO0366 & glf & 0.92 \\
ZMO0369 & glk (glucokinase) & 0.86 \\
ZMO0367 & zwf & 0.79 \\
ZMO1649 & gnl & 0.34 \\
ZMO1757 & gntK & 0.48 \\
ZMO1478 & pgl & 0.67 \\
ZMO0368 & edd & 0.89 \\
ZMO0997 & eda & 0.88 \\
ZMO0177 & gap & 0.97 \\
ZMO0178 & pgk & 0.8 \\
ZMO1240 & gpm & 0.91 \\
ZMO1608 & eno & 0.87 \\
ZMO0152 & pyk & 0.87 \\
ZMO1496 & Ppc & 0.64 \\
ZMO1237 & IdhA & 0.54 \\
ZMO1360 & pdc & 0.76 \\
ZMO1596 & AdhB & 0.89 \\
ZMO0544 & CitC & 0.91 \\
ZMO0487 & Citrate lyase & 0.78 \\
ZMO0569 & FudBC & 0.95 \\
ZMO0705 & GltA & 1.03 \\
ZMO1955 & & 0.91 \\
ZMO1307 & 0.76 \\
ZMO1963 & 0.94 \\
\hline & & \\
\hline
\end{tabular}

NADH:ubiquinone oxidoreductase complex (ZMO1809ZMO1811), fumarate reductase (ZMO0569). Hayashi et al. previously isolated respiratory-deficient mutant (RDM) strains of Z. mobilis, which exhibited higher growth and enhanced ethanol productivity under aerobic conditions. Nucleotide sequence analysis revealed that all $\mathrm{NADH}$ dehydrogenase-deficient strains were mutated within the $n d h$ gene [33]. An upregulation of several thiol-dependent oxidative stress-protective systems was also observed in ndh mutant under aerobically growing [34]. Taken together, knock out $n d h$ gene may be improved Z. mobilis tolerance.

\section{Transcripts of universal stress response gene under ethanol stress}

Z. mobilis contains many ORFs related-to-stress shockresponsive molecular chaperone complex, such as DnaK (ZMO0660), DnaJ (ZMO0661, ZMO1545, ZMO1545, ZMO1069) and GrpE (ZMO0016) of the HSP-70 chaperone complex, GroES-GroEL (ZMO1928 and ZMO1929), HSP-33 (ZMO0410), ZMO0426, ZMO0427,
ZMO0949 and ZMO1424, etc. However, these universal stress genes were not affected significantly under ethanol stress (Data not shown).

On the other hand, sigma factors which are responsible for stress tolerance in $E$. coli were also showed higher differentialy expressed in $Z$. mobilis, such as sigma-E $(\sigma E$, ZMO1404, 1.3-fold), $\sigma 70$ (rpoD, ZMO1623, 1.7-fold), $\sigma 54 \quad$ (rpoN, ZMO0274, 1.2-fold) and $\sigma 28$ (fliA, ZMO0626, 1.4-fold). Seo et al. also supposed that sigmaE plays a key role in resisting high ethanol conditions in Z. mobilis, which was in keeping with our current study about ethanol stress. Further work may be performed by global tanscriptional metabolic engineering (gTME) [35] via $\sigma E$ to improve tolerance in $Z$. mobilis.

\section{Terpenoid biosynthesis under ethanol stress}

Hopanoids are a class of pentacyclic triterpenoid lipids that occur in a wide range of Gram-negative and Grampositive bacteria. Recently study further indicated that hopanoids play an important role in maintaining membrane integrity and $\mathrm{pH}$ homeostasis in Rhodopseudomonas palustris TIE-1 [36]. There are five open reading frames (designated as $h p n A-E$ ) in a close arrangement with shc gene (ZMO0872, the squalene-hopene cyclase, $h p n F)$ [37]. In this study, the genes such as $h p n C$ (ZMO0869) and hpnD (ZMO0870) involving in hopanoid biosynthesis pathway were shown to be downregulated $(0.8$-fold) in the presence of $5 \%$ ethanol after $24 \mathrm{~h}$ incubation. However, hpnA (ZMO0867), hpnB (ZMO0868) and shc were shown to be up-regulated (nearly 1.4-fold) under the same condition.

Other terpenoid biosynthesis related gene, such as ispB (ZMO0564), ispH (ZMO0875), ispE (ZMO1182), hpnH (ZMO0874), hpnI (ZMO0972), hpnJ (ZMO0973), $h p n K(\mathrm{ZMO0974)}$ and $d x r$ (ZMO1150) exhibited a upregulated expression pattern. However, transcripts such as deoD (ZMO0873), dxs (ZMO1234 and ZMO1598), ispDF (ZMO1128), ispG (ZMO0180), ispA (ZMO0855), uppS (ZMO1152), hpnM (ZMO0876) and hpnN (ZMO1599) showed a down-regulated expression pattern.

Previous studies indicated that $Z$. mobilis have the highest total hopanoid content $(30 \mathrm{mg} / \mathrm{g}$ DCW, dry cell weight) among all bacterias, which lead to more tolerant by increasing of the hopanoid content $[38,39]$. However, another research in Z. mobilis ATCC29191 showed that addition of ethanol to the media caused complex changes in the levels of hopanoids and none of the hopanoid lipid classes increased significantly [40]. Carey and Ingram et al. also showed that vaccenic acid represents over $75 \%$ of the acyl chains in the polar membrane lipids in Z. mobilis. Ethanol had no major effect on the fatty acid composition of Z. mobilis, which showed a high constitutive expressed mode even under stress. However, ethanol caused a decrease in phosphatidylethanolamine and 
phosphatidylglycerol, and an increase in cardiolipin and phosphatidylcholine. Ethanol also caused a dosedependent reduction in the lipid-to-protein ratios of crude membranes. These results were in keeping with our array experiment.

Taken together, these data suggest that ethanol has a negative effect on terpenoid biosynthesis, and then may damage the cell membrane of $Z$. mobilis. However, the dynamic changes in lipid composition may represent an evolutionary adaptation for survival in the presence of ethanol [19].

\section{Transcripts of gene related to DNA replication, recombination and repair}

There are 82 ORFs related to DNA replication, recombination and repair in Z. mobilis genome [22]. Five genes related to DNA replication, recombination and repair were revealed as being up-regulated in the presence of $5 \%$ ethanol after 24 h incubation, such as dnaA (ZMO1356), DNA repair protein radC (ZMO1426), ZMO1484, ZMO1417 and ung (ZMO1648) (see Additional file 1: Table S1). Fourty-one genes also showed higer expressed from 1.02 1.99-fold change in this array, such as top $A$ (ZMO1193), ZMO1401, dnaZX (ZMO086), ZMO1582, intZ (ZMO1930), ZMO0888, holA (ZMO1433), xerD (ZMO0598), mutS (ZMO1907), ZMO1194, mutM (ZMO1187), parC (ZMO1054), recF (ZMO1584), ZMO1185, recR (ZMO0812). However, transcripts encoding the others genes related to DNA replication, recombination and repair were found to be less abundant (0.5 0.98 fold change) under ethanol stress, such as $m b o A$ (ZMO0575, 0.54-fold), dnaQ (ZMO0039, 0.53-fold), ihfB (ZMO1801, 0.51-fold) and ZMO1989.

\section{Transcriptional regulation under ethanol stress}

Fifty-four transcriptional activators and repressors were identified in Z. mobilis genome [22]. In this study, 33 transcriptional regulators were down-regulated under ethanol stress. However, only 3 transcriptional regulators including MarR family transcriptional regulator ZMO0054, 1.9-fold) , XRE family transcriptional regulator (ZMO2033, 1.5-fold) and HxlR family transcriptional regulator (ZMO1697, 1.8-fold) showed significant differentialy expressed (see Additional file 1: Table S2).

Transcriptional regulator ZMO1107 (Lrp-like, sharing $40 \%$ identity to $E$. coli global regulator Lrp) and ZMO0347 (sharing 60\% identity to E. coli global regulator $H f q$ ) [31], which also showed less abundant under ethanol stress. Previous studies revealed that E. coli global regulator $\operatorname{Lrp}$ affected the expression of at least $10 \%$ of all E. coli genes [41,42]. Hfq is an RNA-binding protein that is common to diverse bacterial lineages and has key roles in the control of gene expression. Hfq also affected the translation and turnover rates of specific transcripts, which contributes to complex posttranscriptional networks $[31,43]$. Hfq could also associated with $E$. coli motor protein Rho to mediate transcription antitermination via a novel transcription regulatory mechanism [44]. Recently studies also indicated that $H f q$ may play an important role in sRNA network control $[45,46]$. Yang et al. also showed that Z. mobilis $h f q$ contributes to tolerance against multiple lignocellulosic pretreatment inhibitors [47], which provide a fundamental example for further studies or industrial strain development in the future.

Other transcriptional regulators were shown to be more abundant under ethanol stress, such as TetR family transcriptional regulator (ZMO0281, ZMO1547), LysR family transcriptional regulator (ZMO0774) and RpiR family transcriptional regulator (ZMO0190).

Two phage shock protein B and C (ZMO1064, pspB and ZMO1065, $p s p C$ ) were shown to be higher differentially expressed (see Additional file 1: Table S1). Anoter phage shock protein A (ZMO1063, pspA, 1.64-fold) was also showed higer differentially expressed under ethanol stress. These results is in keeping with our previous study on furfural stress [32], which may be indicated that Psp play an important role in response to different stress. There are four phage shock proteins in the ZM4 genome (ZMO1061, ZMO1063, ZMO1064, ZMO1065), which may encode and consist of a psp regulon combined with a hypothetical protein (ZMO1062) [22]. We deduce that there is a $p s p$-like regulon in response to stress in Z. mobilis. Actually, the Phage shock protein response was originally discovered in P. Model's laboratory at the Rockefeller University with studying filamentous phage f1 infection of E. coli [48]. Now, Psp protein is found out across Gram-positive bacteria, Gram-negative bacteria, archaea to plants, and might perceive cell membrane stress and signal to the transcription apparatus by using an ATP hydrolytic transcription activator to produce effector proteins to overcome different stress [49], such as phage infection, secretin production, blockage of protein export or fatty acid/phospholipid biosynthesis, organic solvents, heat, osmotic, $\mathrm{pH}$, etc. [50]. However, function of psp regulon is still unclear, which should be elucidated in the future on molecular level.

\section{Transcripts of gene related to transport systems}

In this study, 12 ORFs related to carbohydrate, amino acid, nucleotide, coenzyme and inorganic ion transport and metabolism showed significant expressed under ethanol stress, such as ZMO1180, ZMO2018, hutG (ZMO1395), ZMO1804, nrdD (ZMO1025), yfeJ (ZMO1855), ZMO1522, thiE (ZMO1425), folK (ZMO1647), ssuC (ZMO1262) and ZMO0546 (see Additional file 1: Table S1). However, 3 ORFs related carbohydrate and coenzyme transport and metabolism showed a down-regulated expression pattern, 
such as gnl (ZMO1649), gntK (ZMO1757) and ZMO0899 (see Additional file 1: Table S2).

\section{Induction of plasmid encoding genes under ethanol stress}

Interestingly, 30 genes from ZM4 plasmids were shown to be more abundant (1.0-2.7 fold, based on $\log _{2}$ system) under ethanol stress condition. However, most of these genes encode hypothetical proteins, such as pzmob1_p05, pzmob1_p06, pzmob1_p07, ZZM4_0013, ZZM4_0026, ZZM4_0027, ZZM4_0114. Especially, pzmob1_p05, pzmob1_p18 and pzmob1_p19 should the same profling between furfural and etanol stress [32].

Five plasmid encoding genes showed less abundant under the same condition (1-1.4 fold, based on $\log _{2}$ system), such as ZZM4_0002, ZZM4_0006, ZZM4_0121, ZZM4_0154 and ZZM4_0156 (see Additional file 1: Table S1 and Table S2). However, pzmob1_p06 and pzmob1_p07 showed more abundant under furfural stress, and less abundant during $5 \%$ ethanol condition. It may be indicated that different plasmid encoding genes are responsible to different stress. Furthermore, the function of plasmid encoding genes are still unclear, and further work should be focing on these genes.

\section{Conclusion}

In this study, we successfully identified genes involved in ethanol tolerance by microarray analysis. These genes were classified as being involved in a wide range of cellular processes including carbohydrate metabolism, cell wall/membrane biogenesis, respiratory chain, terpenoid biosynthesis, DNA replication, DNA recombination, DNA repair, transport, transcriptional regulation, some universal stress response, etc. Our study indicated that ethanol tolerance in $Z$. mobilis is affected by various complicated processes that take place on both the molecular and the cellular level, and that membrane might play important roles in response to ethanol. Although the molecular mechanism involved in tolerance and adaptation of ethanologenic strains to ethanol is still unclear, this research has provided insights into molecular response to ethanol in $Z$. mobilis. These data will also be helpful to construct more ethanol resistant strains for cellulosic ethanol production in the future.

\section{Material and methods}

\section{Bacterial strains and fermentation conditions}

Z. mobilis ZM4 (ATCC31821) was cultured in Rich media (RM) [51] at $30^{\circ} \mathrm{C}$ without shaking. Cultures were maintained on glucose agar $(20.0 \mathrm{~g} / \mathrm{l}$ glucose, $10.0 \mathrm{~g} / \mathrm{l}$ yeast extract and $15.0 \mathrm{~g} / \mathrm{l}$ agar). Organism was subcultured to fresh inoculum media for $24 \mathrm{~h}$ at $30^{\circ} \mathrm{C}$ before being inoculated into the fermentation medium. Inoculum medium ( $\mathrm{g} / \mathrm{l})$ consisted of $10.0 \mathrm{~g}$ yeast extract, $1.0 \mathrm{~g}$
$\mathrm{MgCl}_{2}, 1.0 \mathrm{~g}\left(\mathrm{NH}_{4}\right)_{2} \mathrm{SO}_{4}, 1.0 \mathrm{~g} \mathrm{KH}_{2} \mathrm{PO}_{4}, 20.0 \mathrm{~g}$ glucose. The final concentration of ethanol was set up at $5 \%(\mathrm{v} / \mathrm{v})$ for the study of the response of ethanol stress in $Z$. mobilis. The optical density was measured with a spectrophotometer at $600 \mathrm{~nm}$ with an initial $\mathrm{OD}_{600}$ of 0.05 when the inoculum was added to each flask (with or without $5 \%$ ethanol).

\section{Cell growth and glucose analysis}

Cell growth was determined by monitoring the optical density at $600 \mathrm{~nm}$ by using Multi Scanner Spectrometer (Thermo Inc.) at 4-h intervals. Fermentation supernatant was prepared by passing through $0.2 \mu \mathrm{m}$ membrane (Millipore) and used to determine the concentrations of glucose. Ions Chromatography (Switzerland, Metrohm Bio-Scan 871) was applied to measure the concentration of glucose with sodium hydroxide $(0.1 \mathrm{M})$ as mobile phase at a flow rate of $1.0 \mathrm{ml} / \mathrm{min}$ as described previously [32].

\section{RNA isolation, fluorescein-labeled Cdna and microarray}

Total RNA was isolated essentially described previously $[32,52]$. The RNA quality was assessed by formaldehyde agarose gel electrophoresis and quantitated at $\mathrm{OD}_{260}$ and $\mathrm{OD}_{280}$ by spectrophotometer, respectively. The purified RNA from each sample was used as the template to generate cDNAs while labeled with either Cy3-dUTP or Cy5-dUTP (CapitalBio) in a duplicate set.

Z. mobilis microarrays were constructed by CapitalBio Corporation (Beijing, China) using coding sequences predicted by The Institute for Genomic Research (TIGR, http://www.tigr.org/). Microarray hybridization, washing, scanning and data analysis were carried out according to the NimbleGen's Expression user's guide. Gene expression analysis was performed using six independent microarray experiments (two dye reversal reactions $x$ three biological replicates) with each microarray containing one to two probes per predicted coding sequence each.

Hierarchical clustering and comparison analysis were performed by Cluster 3.0 and SAM 3.02 software, respectively. Sgnificantly differentially expressed genes were determined with a selection threshold of false discovery rate, $\mathrm{FDR}<5 \%$ and fold change $\geq 2.0$ (significant induction) or $\leq 0.5$ (significant repression). Raw data was $\log _{2}$ transformed and imported.

\section{Quantitative-PCR (qPCR) analysis}

Real-time quantitative-PCR (RT-PCR) was performed to verify the microarray expression results. The purified RNA samples were reverse-transcribed by using the Protoscript First Strand cDNA Synthesis Kit (MBI, Fermentas Inc.) as described in the manufacturer's protocol. Based on microarray hybridizations, nighteen genes representing different functional categories and a range 
of gene expression values were selected for qPCR assay (iQ5 Real-Time PCR System, Bio-Rad). Optimized 18-20 bp primers for qPCR analysis listed in Table 1, which were designed to amplify $90-120$ bp of the target genes. Firststrand cDNA was synthesized using a cDNA synthesis kit (MBI, Fermentas Inc.). PCR conditions were $10 \mathrm{~min}$ at $94^{\circ} \mathrm{C}$, followed by 40 cycles of heating at $94^{\circ} \mathrm{C}$ for $20 \mathrm{~s}$ and $60^{\circ} \mathrm{C}$ for $30 \mathrm{~s}$, and final extension at $72^{\circ} \mathrm{C}$ for $5 \mathrm{~min}$. PCR amplification was detected by SYBR fluorescence dye (Takara). The rrsA gene (ZMOr009), encoding the $16 \mathrm{~S}$ ribosomal RNA gene, served as an endogenous control to normalize for differences in total RNA quantity.

\section{Additional files}

Additional file 1: Table S1. Ethanol stress up-regulated genes after 24 $\mathrm{h}$ post inoculation. Table S2. Ethanol stress down-regulated genes after $24 \mathrm{~h}$ post inoculation. Figure S1. Volcano plot result from JMP Genomics analysis showing significantly differentially expressed genes under ethanol stress condition. Green dots indicate down-regulated genes and red dots indicate up-regulated genes. Black colored dots were not considered significantly differentially expressed. The $X$ axis shows the difference values between ethanol stress and normal conditions based on a $\log _{2}$ scale. The $Y$ axis shows statistical significance values for expression values, based on a - $\log 10 p$-value. The grey line shows the statistical significance cut-off used in this study. Figure S2. Comparison of stationary growth phase gene expression measurements by microarray and $\mathrm{gPCR}$. The gene expression ratios for wild-type Z. mobilis ZM4 under ethanol and normal conditions after $24 \mathrm{~h}$ fermentation were log transformed in base 2 . The microarray ratio values were plotted against the $\mathrm{GPCR}$ values. Comparison of the two methods indicated a high level of concordance $(R=0.94)$.

Additional file 2: http://www.ncbi.nlm.nih.gov/geo/query/acc.cgi? token=vrsxbkcsaoiuone\&acc $=$ GSE39558.

\section{Abbreviations}

ED: Entner-Doudoroff; Psp: Phage shock protein.

\section{Competing interests}

The authors declare that they have no competing interests.

\section{Authors' contributions}

He Ming-xiong carried out all of the experiments, participated in the study design and wrote the manuscript. The other authors participated in the design of the study and helped in manuscript writing. All authors read and approved the final manuscript.

\section{Acknowledgments}

This work was supported by grants from the National Natural Science Foundation of China (Grant No. 31000028), Sichuan Key Technology R\&D Program (Grant No. 2009NZ00045) and Sci-tech Fund Project of Chinese Academy of Agricultural Sciences (2009 and 2011).

Received: 20 July 2012 Accepted: 2 October 2012

Published: 11 October 2012

\section{References}

1. Ingram LO, Vreeland NS: Differential effects of ethanol and hexanol on the Escherichia coli cell envelope. J Bacteriol 1980, 144:481-488.

2. Osman YA, Ingram LO: Mechanism of ethanol inhibition of fermentation in Zymomonas mobilis CP4. J Bacteriol 1985, 164(1):173-180.

3. Stanley D, Bandara A, Fraser S, Chambers PJ, Stanley GA: The ethanol stress response and ethanol tolerance of Saccharomyces cerevisiae. J Appl Microbiol 2010, 109(1):13-24.
4. Stanley GA, Hobley TJ, Pamment NB: Effect of acetaldehyde on Saccharomyces cerevisiae and Zymomonas mobilis subjected to environmental shocks. Biotechnol Bioeng 1997, 53:71-78.

5. Piper PW: The heat shock and ethanol stress responses of yeast exhibit extensive similarity and functional overlap. FEMS Microbiol Lett 1995, 134:121-127.

6. Alper H, Moxley J, Nevoigt E, Fink GR, Stephanopoulos G: Engineering yeast transcription machinery for improved ethanol tolerance and production. Science 2006, 314:1565-1568.

7. Watanabe M, Tamura K, Magbanua JP, Takanoc K, Kitamotoc K, Kitagakib H, Akaob T, Shimoia H: Elevated expression of genes under the control of stress response element (STRE) and Msn2p in an ethanol-tolerance sake yeast Kyokai. J Biosci Bioeng 2007, 104:163-170.

8. Alexandre H, Ansanay-Galeote V, Dequin S, Blondin B: Global gene expression during short-term ethanol stress in Saccharomyces cerevisiae. FEBS Lett 2001, 498:98-103.

9. Chandler M, Stanley GA, Rogers PL, Chambers P: A genomic approach to defining the ethanol stress response in the yeast Saccharomyces cerevisiae. Ann Microbiol 2004, 54:427-454.

10. Fujita K, Matsuyama A, Kobayashi Y, Iwahashi H: Comprehensive gene expression analysis of the response to straight-chain alcohols in Saccharomyces cerevisiae using cDNA microarray. J Appl Microbiol 2004, 97:57-67.

11. Stanley D, Chambers P, Stanley G, Borneman A, Fraser S: Transcriptional changes associated with ethanol tolerance in Saccharomyces cerevisiae. Appl Microbiol Biotechnol 2010, 88(1):231-239.

12. Teixeira MC, Raposo LR, Mira NP, Lourenço AB, Sá-Correia I: Genomewide identification of Saccharomyces cerevisiae genes required for maximal tolerance to ethanol. Appl Environ Microbiol 2009, 75(18):5761-5772.

13. Ogawa Y, Nitta A, Uchiyama H, Imamura T, Shimoi H, Ito K: Tolerance mechanism of the ethanol-tolerant mutant of sake yeast. J Biosci Bioeng 2000, 90:313-320.

14. Yoshikawa K, Tanaka T, Furusawa C, Nagahisa K, Hirasawa T, Shimizu H: Comprehensive phenotypic analysis for identification of genes affecting growth under ethanol stress in Saccharomyces cerevisiae. FEMS Yeast Res 2009, 9:32-44

15. Dombek KM, Ingram LO: Effects of ethanol on the Escherichia coli plasma membrane. Journal of Bacteriology 1984, 157(1):233-239.

16. Buttke TM, Ingram LO: Ethanol-induced changes in lipid composition of Escherichia coli: inhibition of saturated fatty acid synthesis in vitro. Arch Biochem Biophys 1980, 203:465-471.

17. Liu S, Qureshi N: How microbes tolerate ethanol and butanol. New Biotechnology 2009, 26(3-4):117-121.

18. Yomano LP, York SW, Ingram LO: Isolation and characterization of ethanol-tolerant mutants of Escherichia coli KO11 for fuel ethanol production. J Ind Microbiol Biotechnol 1998, 20:132-138.

19. Carey VC, Ingram LO: Lipid composition of Zymomonas mobilis: effects of ethanol and glucose. Journal of Bacteriology 1983, 154:1291-1300.

20. Michel GPF, Azoulay T, Starka J: Ethanol effect on the membrane protein pattern of Zymomonas mobilis. Annales de l'Institut Pasteur Microbiologie 1985, 136(2, Supplement 1):173-179.

21. Michel GP, Starka J: Effect of ethanol and heat stresses on the protein pattern of Zymomonas mobilis. Journal of Bacteriology 1986, 165:1040-1042.

22. Seo JS, Chong H, Park HS, Yoon KO, Jung C, Kim JJ, Hong JH, Kim H, Kim JH, Kil Jl, et al: The genome sequence of the ethanologenic bacterium Zymomonas mobilis ZM4. Nature Biotechnol 2005, 23(1):63-68.

23. Jeffries TW: Ethanol fermentation on the move. Nature Biotechnol 2005, 23:40-41.

24. Zhang M, Eddy C, Deanda K, Finkelstein M, Picataggio S: Metabolic engineering of a pentose metabolism pathway in ethanologenic Zymomonas mobilis. Science 1995, 267(5195):240-243.

25. Deanda K, Zhang M, Eddy C, Picataggio S: Development of an arabinosefermenting Zymomonas mobilis strain by metabolic pathway engineering. Appl Env Microbiol 1996, 62(12):4465-4470.

26. Linger JG, Adney WS, Darzins A: Heterologous expression and extracellular secretion of cellulolytic enzymes by Zymomonas mobilis. Appl Environ Microbiol 2010, 76(19):6360-6369.

27. Vasan PT, Piriya PS, Prabhu DI, Vennison SJ: Cellulosic ethanol production by Zymomonas mobilis harboring an endoglucanase gene from Enterobacter cloacae. Bioresour Technol 2011, 102(3):2585-2589. 
28. Kouvelis VN, Saunders E, Brettin TS, Bruce D, Detter C, Han C, Typas MA, Pappas KM: Complete genome sequence of the ethanol producer Zymomonas mobilis NCIMB 11163. Journal of Bacteriology 2009, 191(22):7140-7141.

29. Kouvelis VN, Davenport KW, Brettin TS, Bruce D, Detter C, Han C, Nolan M, Tapia R, Damoulaki A, Kyrpides NC et al:: Genome sequence of the ethanol-producing Zymomonas mobilis subsp. pomaceae lectotype ATCC 29192. Journal of Bacteriology 2011, 193 (18) : 5049-5050

30. Pappas KM, Kouvelis VN, Saunders E, Brettin TS, Bruce D, Detter C, Balakireva M, Han C, Savvakis G, Kyrpides NC et al: Genome sequence of the ethanol-producing Zymomonas mobilis subsp. mobilis lectotype ATCC 10988. Journal of Bacteriology 2011, 193(18):5051-5052.

31. Yang S, Tschaplinski TJ, Engle NL, Carroll SL, Martin SL, Davison BH, Palumbo AV, Rodriguez M Jr, Brown SD: Transcriptomic and metabolomic profiling of Zymomonas mobilis during aerobic and anaerobic fermentations. BMC Genomics 2009, 10:34.

32. He MX, WU B, Shui ZX, Hu QC, Wang WG, Tan FR, Tang XY, Zhu QL, Pan K, $\mathrm{Li} Q$, et al: Transcriptome profiling of Zymomonas mobilis under furfural stress. Appl Microbiol Biotechnol 2012, 95:189-199.

33. Hayashi T, Kato T, Furukawa K: Respiratory chain analysis of high ethanol producing Zymomonas mobilis mutants. Applied and Environmental Microbiology 2012, doi: 10.1128/AEM.00733-12

34. Strazdina I, Kravale Z, Galinina N, Rutkis R, Poole R, Kalnenieks U: Electron transport and oxidative stress in Zymomonas mobilis respiratory mutants. Arch Microbiol 2012, 194(6):461-471.

35. Alper H, Stephanopoulos G: Global transcription machinery engineering: a new approach for improving cellular phenotype. Metab Eng 2007, 9(3):258-267.

36. Welander PV, Hunter RC, Zhang L, Sessions AL, Summons RE, Newman DK: Hopanoids play a role in membrane integrity and $\mathrm{pH}$ homeostasis in Rhodopseudomonas palustris TIE-1. J Bacteriol 2009, 191(19): 6145-6156.

37. Perzl M, Reipen IG, Schmitz S, Poralla K, Sahm H, Sprenger GA, Elmar L: Cloning of conserved genes from Zymomonas mobilis and Bradyrhizobium japonicum that function in the biosynthesis of hopanoid lipids. Biochimica et Biophysica Acta (BBA) - Lipids and Lipid Metabolism 1998, 1393(1):108-118.

38. Hermans MA, Neuss B, Sahm H: Content and composition of hopanoids in Zymomonas mobilis under various growth conditions. J Bacteriol 1991, 173(17):5592-5595.

39. Schmidt A, Bringer-Meyer S, Poralla K, Sahm H: Effect of alcohols and temperature on the hopanoid content of Zymomonas mobilis. Appl Microbiol Biotechnol 1986, 25(1):32-36.

40. Robert AM, Michael JP, William FF: The effect of ethanol and oxygen on the growth of Zymomonas mobilis and the levels of hopanoids and other membrane lipids. Current Microbiology 1997, 35:124-128.

41. Hung SP, Baldi P, Hatfield GW: Global gene expression profiling in Escherichia coli K12. The effects of leucine-responsive regulatory protein. J Biol Chem 2002, 277:40309-40323.

42. Tani TH, Khodursky A, Blumenthal RM, Brown PO, Matthews RG: Adaptation to famine: a family of stationary-phase genes revealed by microarray analysis. Proc Natl Acad Sci USA 2002, 99:13471-13476.

43. Vogel J, Luisi BF: Hfq and its constellation of RNA. Nat Rev Micro 2011, 9(8):578-589.

44. Rabhi M, Espeli O, Schwartz A, Cayrol B, Rahmouni AR, Arluison V, Boudvillain M: The Sm-like RNA chaperone Hfq mediates transcription antitermination at Rho-dependent terminators. Embo J 2011, 30(14):2805-2816.

45. Hussein R, Lim HN: Disruption of small RNA signaling caused by competition for Hfq. P Natl Acad Sci USA 2011, 108(3):1110-1115.

46. Storz G, Vogel J, Wassarman Karen M: Regulation by small RNAs in bacteria: expanding frontiers. Molecular Cell 2011, 43(6):880-891.

47. Yang S, Pelletier DA, Lu TY, Brown SD: The Zymomonas mobilis regulator hfq contributes to tolerance against multiple lignocellulosic pretreatment inhibitors. BMC Microbiol 2010, 10:135.

48. Brissette $J$, Russel M, Weiner L, Model P: Phage shock protein, a stress protein of Escherichia coli. P Natl Acad Sci USA 1990, 87:862-866.

49. Joly N, Engl C, Jovanovic G, Huvet M, Toni T, Sheng X, Stumpf MPH, Buck M: Managing membrane stress: the phage shock protein (Psp) response, from molecular mechanisms to physiology. FEMS Microbiology Reviews 2010, 34(5):797-827.
50. Huvet M, Toni T, Sheng X, Thorne T, Jovanovic G, Engl C, Buck M, Pinney JW, Stumpf MPH: The evolution of the phage shock protein response system: interplay between protein function, genomic organization, and system function. Mol Biol Evol 2011, 28(3):1141-1155.

51. Goodman AE, Rogers PL, Skotnicki ML: Minimal medium for isolation of auxotrophic Zymomonas mutants. Appl Environ Microbiol 1982, 44(2):496-498

52. Chomczynski P: A reagent for the single-step simultaneous isolation of RNA, DNA and proteins from cell and tissue samples. BioTechniques 1993, 15:532-537.

doi:10.1186/1754-6834-5-75

Cite this article as: He et al:: Transcriptome profiling of Zymomonas mobilis under ethanol stress. Biotechnology for Biofuels 2012 5:75.

\section{Submit your next manuscript to BioMed Central and take full advantage of:}

- Convenient online submission

- Thorough peer review

- No space constraints or color figure charges

- Immediate publication on acceptance

- Inclusion in PubMed, CAS, Scopus and Google Scholar

- Research which is freely available for redistribution 